\section{Taxonomic clarity of Indian lizards as a basis for inclusion in checklists: Response to Mirza}

\section{P. Dilip Venugopal}

Department of Entomology, University of Maryland, 4124 Plant Sciences Building, College Park, MD 20742-4454, USA Email:dilip@umd.edu

Mirza (2010) while providing his comments on my original publication on Indian lizards (Venugopal 2010a) put forth some valid suggestions. The primary objectives of my original publication were to verify the validity of Indian lizard species listings based on existence of taxonomic clarity and distributional records within India, while simultaneously providing a comprehensive review of the earlier checklists of Indian reptiles. Additionally, the focus of the manuscript was aimed at highlighting the various modes through which mistakes were perpetuated in species lists and to suggest corrective measures. Therefore, enlisting the Indian lizard species was essentially a product of this exercise. As Mirza (2010) correctly notes, in order to rectify the inadvertent mistake of omitting valid lizard species in this original article, I submitted an addendum (Venugopal 2010b). Despite this, as Mirza (2010) rightfully points, there still have been other valid species erroneously omitted. Cnemaspis kolhapurensis Giri, Bauer \& Gaikwad 2009 and Tropiocolotes persicus euphorbiacola Minton, Anderson \& Anderson 1970 are indeed currently valid listings for Indian lizards and I thank Mirza (2010) for these additions.

Mirza (2010) proposes that Hemidactylus mahendrai be retained in the original list, since it is yet to be formally synonymized with $\mathrm{H}$. brookii (as suggested by Zug et al. 2007), as the type specimens are lost or have not been deposited in a recognized museum. However,

Date of publication (online): 26 May 2010

Date of publication (print): 26 May 2010

ISSN 0974-7907 (online) | 0974-7893 (print)

\section{Manuscript details:}

Ms \# 02463

Received 24 May 2010

Citation: Venugopal, P.D. (2010). Taxonomic clarity of Indian lizards as a basis for inclusion in checklists: Response to Mirza. Journal of Threatened Taxa 2(5): 899-900.

Copyright: (C) P. Dilip Venugopal 2010. Creative Commons Attribution 3.0 Unported License. JoTT allows unrestricted use of this article in any medium for non-profit purposes, reproduction and distribution by providing adequate credit to the authors and the source of publication.

\section{OPEN ACCESS | FREE DOWNLOAD (C) (1) (C)}

Mirza (2010) did not provide any sources or references pertaining to the information on type specimen loss or failure for deposition in a recognized museum. The author cites the paraphyly of $H$. brookii as additional support of his proposition. However, I fail to agree with Mirza's suggestion due to (a) Zug et al. (2007) clearly denote that Shukla's (1983) description of $H$. mahendrai matches that of $H$. brookii, (b) Zug et al. (2010) also mention that the original species description does not differentiate these two species, (c) the type specimen being lost or not deposited in a recognized museum renders the information practically unverifiable. Other species for which type specimen have been lost, and distributional and taxonomic status cannot be verified, have not been included in my original list and, (d) paraphyly of $H$. brookii does not help establish or prove the taxonomic validity of H. mahendrai.

Mirza (2010) adds that Hemidactylus subtriedrus should be retained in the list of Indian reptiles, until it is formally synonymized. On the other hand, the author also comments that it actually belongs to $H$. maculatus complex, thereby rendering the systematic status of $H$. subtriedrus unresolved. This accentuates the lack of certainty in the current taxonomic status of this species, thereby warranting the omission of this species from the checklist. I believe to err on the side of caution and be conservative in the inclusion of species in checklists, enlisting only those with clear taxonomic clarity and distributional records. While it may be useful to provide a checklist also including taxonomically befuddled species, this was not the goal of my original article. As Zug et al (2007) commented this needs further research; therefore, once the taxonomic status of these and other species are known, they then can be added to the list of Indian lizard species. To reiterate Chapman (2005), the taxonomic and nomenclatural information and the spatial information are important considerations for determining data quality and validating species occurrence data. Thus, including Cnemaspis kolhapurensis and Tropiocolotes persicus, the total number of lizard species with valid distributional records and validated taxonomy within Indian limits is 203, comprising of 75 species belonging to Gekkonidae.

\section{REFERENCES}

Chapman, A.D. (2005). Principles of Data Quality version 1.0. Report for the Global Biodiversity Information Facility, Copenhagen. Available at http://www2.gbif.org/DataQuality. pdf. Accessed on 10th July 2008.

Mirza, Z.A. (2010). Comments on "An updated and annotated list of lizards (Reptilia: Sauria) based on a review of distribution records and checklist of Indian reptiles by P.D. Venugopal". Journal of Threatened Taxa 2(5): 898. 
Shukla, V.N. (1983). A new species of the lizard Hemidactylus from Kanpur, India. Indian Journal of Zootomy 24: 81-83.

Venugopal, P.D. (2010a). An updated and annotated list of Indian lizards (Reptilia: Souria) based on a review of distribution records and checklists of Indian reptiles. Journal of Threatened Taxa 2(3): 725-738.

Venugopal, P.D. (2010b). Addendum to An updated and annotated list of Indian lizards (Reptilia: Sauria) based on a review of distribution records and checklists of Indian reptiles. Journal of Threatened Taxa 2(4): 848.

Zug, G.R., J.V. Vindum \& M.S. Koo (2007). Burmese Hemidactylus (Reptilia Squamata Gekkonidae): taxonomic notes on tropical Asian Hemidactylus. Proceedings of the California Academy of Sciences 58: 387-405. 